\title{
Bayer Corneal Epitheliopathy Grade 0
}

National Cancer Institute

\section{Source}

National Cancer Institute. Bayer Corneal Epitheliopathy Grade O. NCI Thesaurus. Code C128437.

No pathologic changes. 